\title{
Neuroprotection in Schizophrenia and Its Therapeutic Implications
}

\author{
Yong-Ku Kim ${ }^{1}$ and Kyoung-Sae $\mathrm{Na}^{2} \bowtie$ \\ 'Department of Psychiatry, College of Medicine, Korea University, Seoul, Republic of Korea \\ ${ }^{2}$ Department of Psychiatry, Gachon University Gil Medical Center, Incheon, Republic of Korea
}

\begin{abstract}
Schizophrenia is a chronic and debilitating mental disorder. The persisting negative and cognitive symptoms that are unresponsive to pharmacotherapy reveal the impairment of neuroprotective aspects of schizophrenia. In this review, of the several neuroprotective factors, we mainly focused on neuroinflammation, neurogenesis, and oxidative stress. We conducted a narrative and selective review. Neuroinflammation is mainly mediated by pro-inflammatory cytokines and microglia. Unlike peripheral inflammatory responses, neuroinflammation has a role in various neuronal activities such as neurotransmission neurogenesis. The cross-talk between neuroinflammation and neurogenesis usually has beneficial effects in the CNS under physiological conditions. However, uncontrolled and chronic neuroinflammation exert detrimental effects such as neuronal loss, inhibited neurogenesis, and excessive oxidative stress. Neurogenesis is also a major component of neuroprotection. Adult neurogenesis mainly occurs in the hippocampal region, which has an important role in memory formation and processing. Impaired neurogenesis and an ineffective response to antipsychotics may be thought to indicate a deteriorating course of schizophrenia. Oxidative stress and excessive dopaminergic neurotransmission may create a vicious cycle and consequently disturb NMDA receptor-mediated glutamatergic neurotransmission. Based on the current evidences, several neuroprotective therapeutic approaches have been reported to be efficacious for improving psychopathology, but further longitudinal and large-sample based studies are needed.

Psychiatry Investig 2017;14(4):383-391
\end{abstract}

Key Words Neuroprotection, Neuroinflammation, Cytokine, Neurogenesis, Schizophrenia.

\section{INTRODUCTION}

Generally, neuroprotection is defined as a mechanism to maintain homeostasis and the functional integrity of the central nervous system (CNS) against any neurodegenerative and neurotoxic insults. ${ }^{1}$ Practically, neuroprotection can also refer to an intervention that helps to restore the functional integrity of the brain in response to neurobiological stress. ${ }^{1}$ Neuroprotection can be facilitated by intrinsic compensatory mechanisms and external treatment approaches. The failure of compensatory neuroprotective processes results in various anatomical and functional impairments in the CNS, including schizophrenia.

Schizophrenia is a debilitating and severe mental illness that affects approximately $1 \%$ of the general population worldwide. ${ }^{2}$

Received: April 18, 2016 Revised: July 4, 2016

Accepted: July 6, 2016 Available online: March 14, 2017

$\triangle$ Correspondence: Kyoung-Sae Na, MD

Department of Psychiatry, Gachon University Gil Medical Center, 21 Namdongdaero 774beon-gil, Namdong-gu, Incheon 21565, Republic of Korea Tel: +82-32-468-9932, Fax: +82-32-468-9962, E-mail: ksna13@gmail.com

(a) This is an Open Access article distributed under the terms of the Creative Commons Attribution Non-Commercial License (http://creativecommons.org/licenses/bync/4.0) which permits unrestricted non-commercial use, distribution, and reproduction in any medium, provided the original work is properly cited.
Schizophrenia is characterized by positive, negative, and cognitive symptoms with poor insight and impaired psychosocial function. ${ }^{3}$ Although acute psychosis is controlled with pharmacotherapy, negative and cognitive symptoms tend to be unresponsive to pharmacotherapy. ${ }^{4-6}$ In addition, most secondgeneration antipsychotics (SGA) except clozapine have been shown to have no significant advantages over first-generation antipsychotics (FGA) even in the domain of negative and cognitive symptoms. ${ }^{7}$ The chronicity and deterioration of the illness raise the possibility that schizophrenia may have neurodegenerative aspects.

Etiological associations with prenatal exposure to infection, ${ }^{8,9}$ obstetric complications, ${ }^{10}$ and genetic vulnerabilities ${ }^{11,12}$ support the notion that schizophrenia has a neurodegenerative etiology. In addition, cortical gray matter loss has been shown to be associated with childhood-onset schizophrenia. ${ }^{13}$ Gray matter loss appears to be slowly progressive, and findings support the underlying neuroanatomical basis of a deteriorating course of the disease. Moreover, functional hypofrontality during working memory-related tasks has been found in the dorsolateral prefrontal cortical region in schizophrenia. ${ }^{14}$

The above considerations suggest that neurobiological vulnerability and impaired neuroprotection greatly contribute 
to the etiopathology of schizophrenia. In this article, we reviewed current evidences suggesting the association between neuroprotection and schizophrenia in the etiological and therapeutic perspectives.

\section{NEUROINFLAMMATION AND NEUROGENESIS OF SCHIZOPHRENIA}

Inflammation has been considered to be a causative factor in schizophrenia, which has been shown to involve a dysregulated cytokine system. Cytokines are pleiotropic glycoproteins produced by both peripheral immune cells and glial cells in the brain. ${ }^{15,16}$ Cytokines usually have an important role in mediating immune signals and inflammatory processes in the peripheral system and in the brain; cytokines also are involved in various neural interactions such as neurogenesis and synaptic plasticity. ${ }^{17,18}$ In this regard, neuroinflammation is distinguished from systematic inflammation. Particularly, pro-inflammatory cytokines such as interleukin-1 $\beta$ (IL-1 $\beta$ ), interleukin-6 (IL-6), and tumor necrosis factor- $\alpha$ (TNF- $\alpha$ ) primarily mediate and facilitate neural activities as well as inflammatory processes. In particular, during the early period of disease development, activated pro-inflammatory cytokines may exert detrimental effects on the brain. There is mounting evidence that prenatal exposure to pro-inflammatory cytokines induces impaired spatial memory, neuronal loss, and gliosis in the hippocampus. ${ }^{19}$ Moreover, neurodevelopmental injuries due to excessive pro-inflammatory cytokines increase susceptibility to schizophrenia. ${ }^{20-22}$

Neurogenesis is defined as a coordinating process of generating new neurons from neural stem cells. ${ }^{23}$ Since the first report from animal studies ${ }^{24}$ and human postmortem studies of the hippocampal region, ${ }^{25}$ numerous studies have focused on adult neurogenesis. Neurogenesis consists of many steps including stem cell proliferation, neuronal differentiation, migration, and ultimately, integration of newly generated neurons into functional neuronal circuitry. ${ }^{26}$ Adult neurogenesis occurs in specific regions including the subventricular zone (SVZ) in the lateral ventricle and the subgranular zone (SGZ) in the dentate gyrus of the hippocampus. Generally, adult hippocampal neurogenesis is significantly and positively associated with cognitive function such as learning and memory function, which are mainly processed in the hippocampus. ${ }^{27-31}$ Several studies have shown that newly-generated neurons in adulthood have a role in synaptic plasticity and cognitive functions in psychiatric diseases including depression and schizophrenia. ${ }^{26,30,32}$ To date, the most widely investigated psychiatric illness in terms of neurogenesis is probably major depressive disorder, although the pathophysiological link is still uncertain. ${ }^{33-35}$ Importantly, pervasive cognitive dysfunction that does not adequately respond to antipsychotics is a distinguishing clinical characteristic of schizophrenia. ${ }^{36-38}$ In fact, there is a possibility that specific molecular and cellular dysfunction in the hippocampus contributes to the development of schizophrenia. ${ }^{39}$ Additionally, decreased hippocampal volume and activity are the most consistent findings of neuroimaging studies of schizophrenia. ${ }^{40,41}$ One previous study has revealed that impaired prefrontal-hippocampal connectivity is associated with impaired spatial working memory in schizophrenia. ${ }^{42}$ In addition, in a postmortem study of human psychiatric patients, neural stem cell proliferation in the dentate gyrus was only impaired in patients with schizophrenia, but not in those with depression. ${ }^{43}$ Another postmortem study revealed that the number of dividing cells is decreased in the SGZ of patients with schizophrenia. ${ }^{44}$ Collectively, molecular and neuroanatomical evidence supports the notion that hippocampal adult neurogenesis is closely associated with schizophrenia.

Interestingly, neurogenesis is closely associated with pro-inflammatory cytokines and neuroinflammation. Pro-inflammatory cytokine receptors are highly aggregated in regions associated with cognitive functioning such as the hippocampus. ${ }^{45,46}$ Pro-inflammatory cytokines and their receptors may inhibit neurogenesis and impair cognitive function. ${ }^{47,48} \mathrm{Nu}-$ merous reports have supported the idea that several pro-inflammatory cytokines affect neurogenesis.

IL- $1 \beta$ has been consistently shown to be associated with neurogenesis in brain, especially in the hippocampal region. ${ }^{49,50}$ It is of note that the inhibition of IL- $1 \beta$ blocks the decrease in neurogenesis caused by acute stress, as well as the anhedonic and antineurogenic effects of chronic stress. ${ }^{49}$ A previous study revealed that sustained hippocampal IL- $1 \beta$ expression has a detrimental effect on adult neurogenesis. ${ }^{51} \mathrm{IL}-1 \beta$ is also known to be involved in the IFN- $\gamma$-induced suppression of neurogenesis. ${ }^{52}$ Leukemia inhibitory factor (LIF) is also an important cytokine involved in schizophrenia. LIF shares glycoprotein 130 (gp130) with other IL-6 cytokine family members. ${ }^{53}$ LIF mainly modulates neuronal activity such as glial cell activity, the inflammatory process, transcription pathways, and neurogenesis. ${ }^{54-56} \mathrm{An}$ appropriate amount of LIF is essential for normal neuronal function. In an animal study, LIF knock-out mice showed decreased astrocyte and microglial cell activities compared to wild type mice. ${ }^{54}$ Various insults to the CNS may induce over-expression of LIF, which may lead to neurobehavioral abnormalities similar to schizophrenia. ${ }^{56}$ Additionally, LIF gene polymorphism is associated with susceptibility to schizophrenia and working memory deficit. ${ }^{57}$

Another cytokine, TNF- $\alpha$, has an important role in neuronal activity in the CNS ${ }^{58,59}$ TNF- $\alpha$ is usually maintained at low level under normal physiological conditions. ${ }^{60}$ However, when the microenvironment in the CNS is altered by injuries 
such as physical head trauma, infection, and ischemic attack, TNF- $\alpha$ is activated by glial cells. ${ }^{61,62}$ Interestingly, TNF- $\alpha$ has a pivotal role in mediating neurogenesis via its receptors, tumor necrosis factor receptor (TNFR)-1 and TNFR-2. Those two receptors are different in several aspects. First, TNFR-1 contains an intracellular 'death domain' and is involved in detrimental effects such as neuronal apoptosis and neurodegeneration, whereas TNFR-2 is usually involved in neuroprotection. $^{63,64}$ Thus, TNFR-1 and TNFR-2 are differentially involved in proliferation and differentiation of hippocampal neural stem cells. TNFR-1 exerts a negative influence on hippocampal adult neurogenesis, ${ }^{65-67}$ whereas TNFR-2 is involved in promoting neurogenesis. ${ }^{68,69}$ TNF- $\alpha$ is also closely associated with synaptic plasticity by inducing $\alpha$-amino-3-hydroxy5-methyl-4-isoxazolepropionic acid (AMPA) receptors that mediate glutamatergic activity. ${ }^{70}$ Because human neural stem cells have both TNFR-1 and TNFR-2, whether neurogenesis is enhanced or inhibited depends on the microenvironment in the CNS and the context of insults.

\section{OXIDATIVE STRESS AND MITOCHONDRIAL DYSFUNCTION IN SCHIZOPHRENIA}

Neuroinflammation is closely associated with excessive oxidative stress. $^{71,72}$ The CNS is more vulnerable to oxidative stress than are other organs. The brain consumes large amounts of oxygen, lacks anti-oxidative compounds, has a high ratio of membrane surface area to cytoplasmic volume, has a high concentration of polyunsaturated fatty uric acids, and contains a large amount of metals. ${ }^{73-76}$ There have been many evidences suggesting that neuroinflammation and oxidative stress have close interactions and play an important role in the pathophysiology of schizophrenia. ${ }^{77-79}$ Reactive oxygen species (ROS), which include superoxide, nitric oxide, and hydrogen peroxide, are highly reactive molecules, and free radicals are naturally created as byproducts of electron transport and energy metabolism. Appropriate duration and amount of ROS activity contribute to enhanced cellular functioning. ${ }^{80}$ However, an imbalance between amounts of ROS and antioxidant system products can result in oxidative damage. ${ }^{81}$ An imbalance between oxidative stress and antioxidants is also demonstrated in schizophrenia. ${ }^{82,83}$ Several studies have reported excessive activity of oxidants ${ }^{84}$ and decreased antioxidants in patients with schizophrenia. ${ }^{85}$

Antioxidants consist of enzymatic and non-enzymatic materials. Enzymatic antioxidants include superoxide dismutase (SOD), catalase, and glutathione dismutase. Non-enzymatic antioxidants are albumin, uric acid, bilirubin, vitamin C, vitamin $\mathrm{E}$, and $\beta$-carotene. In particular, glutathione plays a major role in the redox process. ${ }^{86}$ Glutathione exerts various effects in the CNS including directly detoxifying drugs, ROS, and electrophilic xenobiotics; storing cysteine; promoting neurodevelopment; and enhancing excitatory glutamatergic neurotransmission..$^{87-89}$

The possible actions by which a deficit of glutathione contributes to the development of schizophrenia may be through NMDA receptors. Dysregulation of dopaminergic neurotransmission and hypofunction of NMDA receptor activity are regarded as the core mechanisms of schizophrenia. ${ }^{90}$ Under normal physiological conditions, glutathione enhances NMDA receptor-mediated glutamatergic neurotransmission. Many animal studies have reported that glutathione exerts an agonistic effect on NMDA receptors. ${ }^{87,91}$ However, in the presence of uncontrolled and persistent chronic oxidative stress, glutathione level is decreased and leads to NMDA receptor dysfunction. ${ }^{92,93}$ Deficits in glutathione level are associated with neurological deficits in various neuropsychiatric diseases. ${ }^{94}$ Glutathione regulates redox-sensitive sites such as the NMDA receptor. Further, a key glutathione-synthesizing enzyme, glutathione cysteine ligase modifier (GCLM), is decreased under oxidative stress. ${ }^{95}$ GCL dysregulation and deficit glutathione inhibit the detoxification of oxidative stress that results from dopamine metabolism and consequently lead to neural injury, especially in dopamine neuron-rich regions. ${ }^{96,97}$ Glutathione is reduced in the prefrontal cortex and striatum, ${ }^{94,98-100}$ which are closely associated with the psychopathology of schizophrenia. Many studies have shown that a deficit in glutathione is associated with psychopathology and clinical variables in schizophrenia. ${ }^{100-102}$

Mitochondrial dysfunction, which is closely associated with oxidative stress, is also associated with neurodegenerative change in schizophrenia. Mitochondria are mainly involved in producing energy via the electron transport chain during the process of oxidative phosphorylation. Mitochondria also regulate intracellular calcium homeostasis and apoptosis. Neurons require the large amount of energy that is mainly produced by the mitochondrial respiratory system in order to maintain the ion gradient between the extracellular and intracellular membranes. Several studies have reported that genetic and structural abnormalities of mitochondria are associated with various psychiatric diseases. ${ }^{103,104}$ In particular, psychosis and cognitive deterioration are common features of mitochondrial diseases such as mitochondrial myopathy, encephalopathy, lactic acidosis, and stroke-like episodes (MELAS) syndrome. ${ }^{105}$

Mitochondrial metabolism is also important for producing ROS. In particular, mitochondrial DNA is vulnerable to oxidative stress because it is located in the mitochondrial inner membrane, where a substantial amount of ROS is produced. ${ }^{106}$ 
Mitochondrial injury and oxidative stress form a vicious cycle. Mitochondria injured by excessive oxidants produce a greater amount of ROS, which leads them to be more vulnerable to oxidative stress. ${ }^{107}$ For example, an overload of oxidative stress causes lipid peroxidation. Lipid peroxidation of the mitochondrial membrane produces toxic molecules such as 4-hydroxynonenal and malondialdehyde, which in turn disturb mitochondrial membrane fluidity. ${ }^{108,109}$ The impaired mitochondrial membrane leads to dysregulation in ionic balances and excessive intracellular calcium influx, which consequently causes neuronal death and impairs synaptic plasticity. ${ }^{110-112}$

\section{NEUROPROTECTIVE AND ANTI-INFLAMMATORY THERAPY IN SCHIZOPHRENIA}

Randomized controlled trials have investigated the efficacy of adjuvant COX-2 inhibitor on antipsychotics treatment in schizophrenia. Of the four extant studies, three have reported significant improvement in psychopathology, ${ }^{113-115}$ whereas one study showed no significant efficacy of COX-2. ${ }^{116}$ An improvement in psychiatric symptoms with anti-inflammatory treatment may be associated with the duration of illness. Whereas the three studies finding a significant therapeutic efficacy of the COX-2 inhibitor were based on patients with a short illness period, ${ }^{113-115}$ the one study with a negative result was conducted with patients with relatively chronic schizophrenia. ${ }^{116}$

Table 1. Evidences supporting relationship between oxidative stress and schizophrenia

\begin{tabular}{|c|c|c|}
\hline Study & Measurements & Main findings \\
\hline \multicolumn{3}{|c|}{ Alterations in the antioxidants and oxidants in schizophrenia } \\
\hline $\begin{array}{l}\text { Yao et al. } \\
\text { (2006) }\end{array}$ & Brain (Postmortem) & $\begin{array}{l}\text { Glutathione, glutathione peroxidase, and glutathione reductase were significantly } \\
\text { lower in the caudate regions of postmortem brains from schizophrenia than controls. }\end{array}$ \\
\hline $\begin{array}{l}\text { Matsuzawa } \\
(2008)\end{array}$ & $\begin{array}{l}\text { Brain }\left({ }^{1} \mathrm{H} \text {-magnetic }\right. \\
\text { resonance spectroscopy) }\end{array}$ & $\begin{array}{l}\text { Glutathione levels in the posterior medial frontal cortex had significant negative } \\
\text { correlation with the severity of negative symptoms in schizophrenia. }\end{array}$ \\
\hline Study & Measures/intervention & Main findings \\
\hline
\end{tabular}

Antioxidative effects of antipsychotics

Dakhale et al. Non-comparative, one sample

Wang et al. In vitro (PC12 cells)

(2005)

Padurariu et al. Cross-sectional, (2010) case-control

Park et al. In vitro (PC12 cells)
Atypical antipsychotics (clozapine, risperidone, olanzapine, quetiapine, ziprasidone) treatment significantly reduced serum malondialdehyde and superoxide dismutase levels in schizophrenia after 8 weeks.

Olanzapine and quetiapine reduced intracellular reactive oxygen species caused by $\beta$-amyloid.

Olanzapine and quetiapine completely prevented $\beta$-amyloid-induced reduction of glutathione peroxidase.

Glutathione peroxidase specific activity and malondialdehyde levels were significantly higher in all antipsychotics (haloperidol, olanzapine, quetiapine, risperidone) groups than healthy controls.

Superoxide dismutase specific activity was significantly higher in haloperidol and quetiapine than healthy controls.

Aripiprazole significantly reduced 1-methyl-4-phenylpyridinium-induced cell death. Olanzapine, aripiprazole, and ziprasidone significantly increased superoxide dismutase activity, whereas haloperidol had no significant effects.

\begin{tabular}{|c|c|c|}
\hline Study & Intervention & Main findings \\
\hline \multicolumn{3}{|c|}{ Therapeutic effects of antioxidants in schizophrenia } \\
\hline $\begin{array}{l}\text { Beck et al. } \\
(2008)\end{array}$ & $\begin{array}{l}\text { NAC } \\
2 \text { g/day }\end{array}$ & $\begin{array}{l}\text { NAC significantly improved negative symptoms, but not positive symptoms than } \\
\text { placebo. } \\
\text { NAC significantly improved akathisia. }\end{array}$ \\
\hline $\begin{array}{l}\text { Lavoie et al. } \\
\text { (2008) }\end{array}$ & NAC 2 g/day & NAC significantly improved mismatch negativity of the encephalograph than placebo. \\
\hline $\begin{array}{l}\text { Carmeli et al. } \\
(2012)\end{array}$ & NAC 2 g/day & $\begin{array}{l}\text { NAC significantly increased multivariate phase synchronization in the left } \\
\text { parieto-occipital, right temporalm bilateral prefrontal regions than placebo. }\end{array}$ \\
\hline
\end{tabular}

NAC: N-acetyl cysteine 
A meta-analysis showed that augmentation of anti-inflammatory drugs to the antipsychotics would be a potential therapeutic options in patients with schizophrenia, although more evidences should be accumulated. ${ }^{117}$

Several antioxidant treatment approaches have reported that antioxidants are effective for improving psychopathology in schizophrenia. Because glutathione is not bioavailable, it is not possible to able to be directly used. Instead, N-acetyl cysteine (NAC), which is a glutathione precursor, has been used for schizophrenic patients. A double-blind, placebo-controlled study demonstrated that NAC ( 2 g/day) ameliorated negative symptoms, but not positive symptoms in patients with chronic schizophrenia. ${ }^{118}$ Another double-blind, placebo-controlled study revealed that NAC improved mismatch negativity, which is associated with NMDA receptor function, in patients with schizophrenia. ${ }^{119}$

Several studies have consistently reported that ginkgo biloba augmented with haloperidol improves negative symptoms and increases SOD level in patients who experience chronic hospitalizations and treatment resistance due to schizophrenia. ${ }^{120-122}$ A meta-analysis revealed that ginkgo as an add-on treatment to antipsychotics significantly improved total and negative symptoms in patients with chronic schizophrenia. ${ }^{123}$

Several studies have reported that schizophrenia is associated with low serum vitamin C levels. ${ }^{124-126}$ A previous doubleblind, placebo-controlled study showed that a vitamin C (500 $\mathrm{mg} /$ day) supplement with atypical antipsychotics (olanzapine $10 \mathrm{mg}$ /day, quetiapine $200 \mathrm{mg} /$ day, or ziprasidone $40 \mathrm{mg}$ /day) significantly decreased serum malondialdehyde (MDA) level and psychopathology compared to a placebo add-on group. ${ }^{127}$

Antipsychotics have been thought to have anti-inflammatory properties. In a meta-analysis of patients with acute relapse or first onset schizophrenia, levels of peripheral pro-in- flammatory cytokines including IL-6, IL- $1 \beta$, and IFN- $\gamma$ were significantly decreased after antipsychotic treatment compared to baseline. ${ }^{128}$ Those results are in line with previous studies reporting that both typical and atypical antipsychotics suppress microglial activation, thus inhibiting inflammatory mediators. ${ }^{129-133}$

Antipsychotics also enhance neurogenesis. In one study, chronic treatment with a low dose of clozapine $(0.5 \mathrm{mg} / \mathrm{kg})$ increased the number of bromodeoxyuridine (BrdU)-positive cells in the dentate gyrus 24 hours after BrdU administration, whereas haloperidol ( 0.05 or $2 \mathrm{mg} / \mathrm{kg}$ ) or a high dose of clozapine $(20 \mathrm{mg} / \mathrm{kg})$ had no significant effect. ${ }^{134}$ Interestingly, the increased BrdU-positive cells with a low dose of clozapine could not survive or integrate into existing hippocampal circuitry. These intriguing results suggest that antipsychotics influence neuronal proliferation, but not survival. It has been speculated that the limitations of the effect of antipsychotics on neurogenesis may be associated with an insufficient treatment response in terms of negative and cognitive symptoms, as well as a deteriorating course of schizophrenia. At the same time, antipsychotics demonstrate antioxidant effects. ${ }^{135-138}$ One study group has consistently reported that initial SOD level in schizophrenia was lower than that in controls, and both typical and atypical antipsychotics significantly increase SOD level. ${ }^{72,139-141}$ The improvement in the psychopathology of patients with schizophrenia has been correlated with the degree of change in SOD level. Although the mechanisms by which antipsychotics exert antioxidant effects still have not been clearly identified, differences between typical and atypical antipsychotics appear insignificant. ${ }^{135,141}$ The aforementioned evidences supporting the relationships between oxidative stress and schizophrenia were summarized in Table 1.

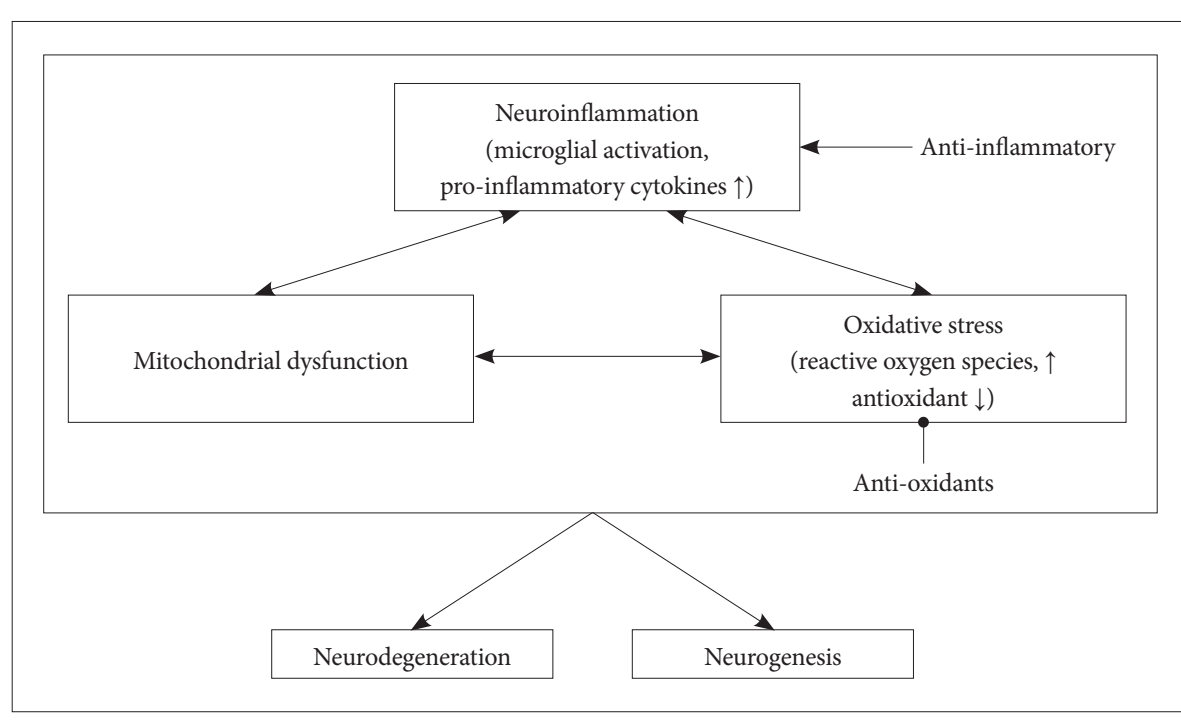

Figure 1. Relationships among neuroinflammation, oxidative stress, and mitochondrial dysfunction for neurodegeneration and impaired neurogenesis in schizophrenia. The round shape arrow indicates inhibiting role, whereas the triangle shape arrow indicates facilitating role. 


\section{CONCLUSION}

Current evidence clearly supports a close link between neuroprotection and the onset and symptoms of schizophrenia. Several factors affecting neuroprotection, which include neuroinflammation, neurogenesis, and oxidative stress, appear to increase vulnerability to schizophrenia (Figure 1). However, there are several issues in the field of neuroprotection in schizophrenia. First, the measurements of pro-inflammatory cytokines, oxidative stress markers, and neural cell proliferations may not suitable for distinguishing schizophrenia from other neuropsychiatric diseases. Second, despite several clinical findings supporting the effectiveness of adjuvant antioxidant and anti-inflammatory agents, further longitudinal studies and studies with a large sample are needed. Third, the heterogeneous subtypes of schizophrenia should also be considered limiting factors of schizophrenia-specific findings.

\section{REFERENCES}

1. Lieberman JA, Jarskog LF, Malaspina D. Preventing clinical deterioration in the course of schizophrenia: the potential for neuroprotection. J Clin Psychiatry 2006;67:983-990.

2. Perala J, Suvisaari J, Saarni SI, Kuoppasalmi K, Isometsa E, Pirkola S, et al. Lifetime prevalence of psychotic and bipolar I disorders in a general population. Arch Gen Psychiatry 2007;64:19-28.

3. Monteiro LC, Silva VA, Louza MR. Insight, cognitive dysfunction and symptomatology in schizophrenia. Eur Arch Psychiatry Clin Neurosci 2008;258:402-405.

4. Ibrahim HM, Tamminga CA. Treatment of cognitive dysfunction in schizophrenia. Curr Pharm Biotechnol 2012;13:1587-1594.

5. Hanson E, Healey K, Wolf D, Kohler C. Assessment of pharmacotherapy for negative symptoms of schizophrenia. Curr Psychiatry Rep 2010; 12:563-571

6. Webber MA, Marder SR. Better pharmacotherapy for schizophrenia: what does the future hold? Curr Psychiatry Rep 2008;10:352-358.

7. Lieberman JA, Stroup TS, McEvoy JP, Swartz MS, Rosenheck RA, Perkins DO, et al. Effectiveness of antipsychotic drugs in patients with chronic schizophrenia. N Engl J Med 2005;353:1209-1223.

8. Markham JA, Koenig JI. Prenatal stress: role in psychotic and depressive diseases. Psychopharmacology (Berl) 2011;214:89-106.

9. Brown AS. Exposure to prenatal infection and risk of schizophrenia. Front Psychiatry 2011;2:63.

10. Bersani G, Quartini A, Manuali G, Iannitelli A, Pucci D, Conforti F, et al. Influence of obstetric complication severity on brain morphology in schizophrenia: an MR study. Neuroradiology 2009;51:363-371.

11. Murray RM, Reveley AM, McGuffin P. Genetic vulnerability to schizophrenia. Psychiatr Clin North Am 1986;9:3-16.

12. Delisi LE. Searching for the true genetic vulnerability for schizophrenia. Genome Med 2009;1:14.

13. Thompson PM, Vidal C, Giedd JN, Gochman P, Blumenthal J, Nicolson R, et al. Mapping adolescent brain change reveals dynamic wave of accelerated gray matter loss in very early-onset schizophrenia. Proc Natl Acad Sci U S A 2001;98:11650-11655.

14. Carter CS, Perlstein W, Ganguli R, Brar J, Mintun M, Cohen JD. Functional hypofrontality and working memory dysfunction in schizophrenia. Am J Psychiatry 1998;155:1285-1287.

15. Ozaki K, Leonard WJ. Cytokine and cytokine receptor pleiotropy and redundancy. J Biol Chem 2002;277:29355-29358.

16. Watkins LR, Maier SF, Goehler LE. Cytokine-to-brain communica- tion: a review \& analysis of alternative mechanisms. Life Sci 1995;57: 1011-1026.

17. Vitkovic L, Bockaert J, Jacque C. "Inflammatory" cytokines: neuromodulators in normal brain? J Neurochem 2000;74:457-471.

18. Seguin JA, Brennan J, Mangano E, Hayley S. Proinflammatory cytokines differentially influence adult hippocampal cell proliferation depending upon the route and chronicity of administration. Neuropsychiatr Dis Treat 2009;5:5-14.

19. Samuelsson AM, Jennische E, Hansson HA, Holmang A. Prenatal exposure to interleukin- 6 results in inflammatory neurodegeneration in hippocampus with NMDA/GABA(A) dysregulation and impaired spatial learning. Am J Physiol Regul Integr Comp Physiol 2006;290: R1345-R1356.

20. Brown AS. Prenatal infection as a risk factor for schizophrenia. Schizophr Bull 2006;32:200-202.

21. Brown AS, Derkits EJ. Prenatal infection and schizophrenia: a review of epidemiologic and translational studies. Am J Psychiatry 2010;167: 261-280.

22. Gilmore JH, Fredrik Jarskog L, Vadlamudi S, Lauder JM. Prenatal infection and risk for schizophrenia: IL-1beta, IL-6, and TNFalpha inhibit cortical neuron dendrite development. Neuropsychopharmacology 2004;29:1221-1229.

23. Emsley JG, Mitchell BD, Kempermann G, Macklis JD. Adult neurogenesis and repair of the adult CNS with neural progenitors, precursors, and stem cells. Prog Neurobiol 2005;75:321-341.

24. Altman J, Das GD. Autoradiographic and histological evidence of postnatal hippocampal neurogenesis in rats. J Comp Neurol 1965;124: 319-335.

25. Eriksson PS, Perfilieva E, Bjork-Eriksson T, Alborn AM, Nordborg C, Peterson DA, et al. Neurogenesis in the adult human hippocampus. Nat Med 1998;4:1313-1317.

26. Ming GL, Song H. Adult neurogenesis in the mammalian central nervous system. Annu Rev Neurosci 2005;28:223-250.

27. Deng W, Aimone JB, Gage FH. New neurons and new memories: how does adult hippocampal neurogenesis affect learning and memory? Nat Rev Neurosci 2010;11:339-350.

28. Leuner B, Gould E, Shors TJ. Is there a link between adult neurogenesis and learning? Hippocampus 2006;16:216-224.

29. Rossol M, Kraus S, Pierer M, Baerwald C, Wagner U. The CD14(bright) CD16+ monocyte subset is expanded in rheumatoid arthritis and promotes Th17 expansion. Arthritis Rheum 2012;64:671-677.

30. Kempermann G. Why new neurons? Possible functions for adult hippocampal neurogenesis. J Neurosci 2002;22:635-638.

31. Jensen O, Lisman JE. Hippocampal sequence-encoding driven by a cortical multi-item working memory buffer. Trends Neurosci 2005;28: 67-72.

32. DeCarolis NA, Eisch AJ. Hippocampal neurogenesis as a target for the treatment of mental illness: a critical evaluation. Neuropharmacology 2010;58:884-893.

33. Vollmayr B, Mahlstedt MM, Henn FA. Neurogenesis and depression: what animal models tell us about the link. Eur Arch Psychiatry Clin Neurosci 2007;257:300-303.

34. Henn FA, Vollmayr B. Neurogenesis and depression: etiology or epiphenomenon? Biol Psychiatry 2004;56:146-150.

35. Duman RS. Depression: a case of neuronal life and death? Biol Psychiatry 2004;56:140-145.

36. Goldman-Rakic PS. Working memory dysfunction in schizophrenia. J Neuropsychiatry Clin Neurosci 1994;6:348-357.

37. Barch DM. What can research on schizophrenia tell us about the cognitive neuroscience of working memory? Neuroscience 2006;139:73-84.

38. Frantseva MV, Fitzgerald PB, Chen R, Moller B, Daigle M, Daskalakis ZJ. Evidence for impaired long-term potentiation in schizophrenia and its relationship to motor skill learning. Cereb Cortex 2008;18:990-996.

39. Weinberger DR. Cell biology of the hippocampal formation in schizophrenia. Biol Psychiatry 1999;45:395-402. 
40. Vita A, De Peri L, Silenzi C, Dieci M. Brain morphology in first-episode schizophrenia: a meta-analysis of quantitative magnetic resonance imaging studies. Schizophr Res 2006;82:75-88.

41. Heckers S. Neuroimaging studies of the hippocampus in schizophrenia. Hippocampus 2001;11:520-528.

42. Sigurdsson T, Stark KL, Karayiorgou M, Gogos JA, Gordon JA. Impaired hippocampal-prefrontal synchrony in a genetic mouse model of schizophrenia. Nature 2010;464:763-767.

43. Reif A, Fritzen S, Finger M, Strobel A, Lauer M, Schmitt A, et al. Neural stem cell proliferation is decreased in schizophrenia, but not in depression. Mol Psychiatry 2006;11:514-522.

44. Ross CA, Margolis RL, Reading SA, Pletnikov M, Coyle JT. Neurobiology of schizophrenia. Neuron 2006;52:139-153.

45. Parnet P, Kelley KW, Bluthe RM, Dantzer R. Expression and regulation of interleukin-1 receptors in the brain. Role in cytokines-induced sickness behavior. J Neuroimmunol 2002;125:5-14.

46. Haour F, Jafarian-Tehrani M, Gabellec MM, Crumeyrolle-Arias M, Hu Y, Wick G, et al. Interleukin-1 receptor defect in autoimmune NZB mouse brain. Ann N Y Acad Sci 1998;840:755-761.

47. Barrientos RM, Higgins EA, Biedenkapp JC, Sprunger DB, WrightHardesty KJ, Watkins LR, et al. Peripheral infection and aging interact to impair hippocampal memory consolidation. Neurobiol Aging 2006; 27:723-732.

48. Arai K, Matsuki N, Ikegaya Y, Nishiyama N. Deterioration of spatial learning performances in lipopolysaccharide-treated mice. Jpn J Pharmacol 2001;87:195-201.

49. Koo JW, Duman RS. IL-1beta is an essential mediator of the antineurogenic and anhedonic effects of stress. Proc Natl Acad Sci U S A 2008; 105:751-756.

50. Kuzumaki N, Ikegami D, Imai S, Narita M, Tamura R, Yajima M, et al. Enhanced IL-1beta production in response to the activation of hippocampal glial cells impairs neurogenesis in aged mice. Synapse 2010;64: 721-728.

51. Wu MD, Hein AM, Moravan MJ, Shaftel SS, Olschowka JA, O’Banion MK. Adult murine hippocampal neurogenesis is inhibited by sustained IL-1beta and not rescued by voluntary running. Brain Behav Immun 2012;26:292-300.

52. Kaneko N, Kudo K, Mabuchi T, Takemoto K, Fujimaki K, Wati H, et al. Suppression of cell proliferation by interferon-alpha through interleukin-1 production in adult rat dentate gyrus. Neuropsychopharmacology 2006;31:2619-2626.

53. Taga T, Kishimoto T. Gp130 and the interleukin-6 family of cytokines. Annu Rev Immunol 1997;15:797-819.

54. Holmberg KH, Patterson PH. Leukemia inhibitory factor is a key regulator of astrocytic, microglial and neuronal responses in a low-dose pilocarpine injury model. Brain Res 2006;1075:26-35.

55. Kerr BJ, Patterson PH. Potent pro-inflammatory actions of leukemia inhibitory factor in the spinal cord of the adult mouse. Exp Neurol 2004;188:391-407.

56. Watanabe Y, Hashimoto S, Kakita A, Takahashi H, Ko J, Mizuno M, et al. Neonatal impact of leukemia inhibitory factor on neurobehavioral development in rats. Neurosci Res 2004;48:345-353.

57. Okahisa Y, Ujike H, Kunugi H, Ishihara T, Kodama M, Takaki M, et al. Leukemia inhibitory factor gene is associated with schizophrenia and working memory function. Prog Neuropsychopharmacol Biol Psychiatry 2010;34:172-176.

58. Aharoni R, Arnon R, Eilam R. Neurogenesis and neuroprotection induced by peripheral immunomodulatory treatment of experimental autoimmune encephalomyelitis. J Neurosci 2005;25:8217-8228.

59. Turrin NP, Rivest $\mathrm{S}$. Tumor necrosis factor alpha but not interleukin 1 beta mediates neuroprotection in response to acute nitric oxide excitotoxicity. J Neurosci 2006;26:143-151.

60. Pitossi F, del Rey A, Kabiersch A, Besedovsky H. Induction of cytokine transcripts in the central nervous system and pituitary following peripheral administration of endotoxin to mice. J Neurosci Res 1997;
48:287-298.

61. Munoz-Fernandez MA, Fresno M. The role of tumour necrosis factor, interleukin 6, interferon-gamma and inducible nitric oxide synthase in the development and pathology of the nervous system. Prog Neurobiol 1998; 56:307-340.

62. Sheng W, Zong Y, Mohammad A, Ajit D, Cui J, Han D, et al. Pro-inflammatory cytokines and lipopolysaccharide induce changes in cell morphology, and upregulation of ERK1/2, iNOS and sPLA-IIA expression in astrocytes and microglia. J Neuroinflammation 2011; 8:121.

63. Yang L, Lindholm K, Konishi Y, Li R, Shen Y. Target depletion of distinct tumor necrosis factor receptor subtypes reveals hippocampal neuron death and survival through different signal transduction pathways. J Neurosci 2002;22:3025-3032.

64. Marchetti L, Klein M, Schlett K, Pfizenmaier K, Eisel UL. Tumor necrosis factor (TNF)-mediated neuroprotection against glutamate-induced excitotoxicity is enhanced by $\mathrm{N}$-methyl-D-aspartate receptor activation. Essential role of a TNF receptor 2-mediated phosphatidylinositol 3-kinase-dependent NF-kappa B pathway. J Biol Chem 2004;279:32869-32881.

65. Ben-Hur T, Ben-Menachem O, Furer V, Einstein O, Mizrachi-Kol R, Grigoriadis N. Effects of proinflammatory cytokines on the growth, fate, and motility of multipotential neural precursor cells. Mol Cell Neurosci 2003;24:623-631.

66. Dybedal I, Bryder D, Fossum A, Rusten LS, Jacobsen SE. Tumor necrosis factor (TNF)-mediated activation of the p55 TNF receptor negatively regulates maintenance of cycling reconstituting human hematopoietic stem cells. Blood 2001;98:1782-1791.

67. Iosif RE, Ekdahl CT, Ahlenius H, Pronk CJ, Bonde S, Kokaia Z, et al. Tumor necrosis factor receptor 1 is a negative regulator of progenitor proliferation in adult hippocampal neurogenesis. J Neurosci 2006;26: 9703-9712.

68. Chen J, Jacobs-Helber SM, Barber DL, Sawyer ST. Erythropoietin-dependent autocrine secretion of tumor necrosis factor-alpha in hematopoietic cells modulates proliferation via MAP kinase--ERK-1/2 and does not require tyrosine docking sites in the EPO receptor. Exp Cell Res 2004;298:155-166.

69. Arnett HA, Mason J, Marino M, Suzuki K, Matsushima GK, Ting JP. TNF alpha promotes proliferation of oligodendrocyte progenitors and remyelination. Nat Neurosci 2001;4:1116-1122.

70. Beattie EC, Stellwagen D, Morishita W, Bresnahan JC, Ha BK, Von Zastrow M, et al. Control of synaptic strength by glial TNFalpha. Science 2002;295:2282-2285.

71. Yao JK, van Kammen DP. Membrane phospholipids and cytokine interaction in schizophrenia. Int Rev Neurobiol 2004;59:297-326.

72. Zhang XY, Zhou DF, Qi LY, Chen S, Cao LY, Chen DC, et al. Superoxide dismutase and cytokines in chronic patients with schizophrenia: association with psychopathology and response to antipsychotics. Psychopharmacology (Berl) 2009;204:177-184.

73. Mahadik SP, Mukherjee S. Free radical pathology and antioxidant defense in schizophrenia: a review. Schizophr Res 1996;19:1-17.

74. Rougemont M, Do KQ, Castagne V. New model of glutathione deficit during development: Effect on lipid peroxidation in the rat brain. J Neurosci Res 2002;70:774-783.

75. McQuillen PS, Ferriero DM. Selective vulnerability in the developing central nervous system. Pediatr Neurol 2004;30:227-235.

76. Berg D, Youdim MB, Riederer P. Redox imbalance. Cell Tissue Res 2004;318:201-213.

77. Anderson G. Neuronal-immune interactions in mediating stress effects in the etiology and course of schizophrenia: role of the amygdala in developmental co-ordination. Med Hypotheses 2011;76:54-60.

78. Anderson G, Berk M, Dodd S, Bechter K, Altamura AC, Dellosso B, et al. Immuno-inflammatory, oxidative and nitrosative stress, and neuroprogressive pathways in the etiology, course and treatment of schizophrenia. Prog Neuropsychopharmacol Biol Psychiatry 2013;42:1-4. 
79. Galecki P, Pietras T, Szemraj J, Florkowska K, Florkowski A, Zboralski K. [Functional polymorphism of manganese superoxide dismutase (MnSOD) gene correlates with schizophrenia in Polish population]. Pol Merkur Lekarski 2006;20:329-332.

80. Sundaresan M, Yu ZX, Ferrans VJ, Irani K, Finkel T. Requirement for generation of $\mathrm{H} 2 \mathrm{O} 2$ for platelet-derived growth factor signal transduction. Science 1995;270:296-299.

81. Wallace DC. A mitochondrial paradigm of metabolic and degenerative diseases, aging, and cancer: a dawn for evolutionary medicine. Annu Rev Genet 2005;39:359-407.

82. Dadheech G, Mishra S, Gautam S, Sharma P. Evaluation of antioxidant deficit in schizophrenia. Indian J Psychiatry 2008;50:16-20.

83. Zhang XY, Tan YL, Cao LY, Wu GY, Xu Q, Shen Y, et al. Antioxidant enzymes and lipid peroxidation in different forms of schizophrenia treated with typical and atypical antipsychotics. Schizophr Res 2006;81: 291-300.

84. Zhang XY, Zhou DF, Cao LY, Zhang PY, Wu GY. Elevated blood superoxide dismutase in neuroleptic-free schizophrenia: association with positive symptoms. Psychiatry Res 2003;117:85-88.

85. Virit O, Altindag A, Yumru M, Dalkilic A, Savas HA, Selek S, et al. A defect in the antioxidant defense system in schizophrenia. Neuropsychobiology 2009;60:87-93.

86. Schafer FQ, Buettner GR. Redox environment of the cell as viewed through the redox state of the glutathione disulfide/glutathione couple. Free Radic Biol Med 2001;30:1191-1212.

87. Kohr G, Eckardt S, Luddens H, Monyer H, Seeburg PH. NMDA receptor channels: subunit-specific potentiation by reducing agents. Neuron 1994;12:1031-1040.

88. Meister A. Glutathione metabolism and its selective modification. J Biol Chem 1988;263:17205-17208.

89. Shi ZZ, Osei-Frimpong J, Kala G, Kala SV, Barrios RJ, Habib GM, et al. Glutathione synthesis is essential for mouse development but not for cell growth in culture. Proc Natl Acad Sci U S A 2000;97:5101-5106.

90. Kristiansen LV, Huerta I, Beneyto M, Meador-Woodruff JH. NMDA receptors and schizophrenia. Curr Opin Pharmacol 2007;7:48-55.

91. Leslie SW, Brown LM, Trent RD, Lee YH, Morris JL, Jones TW, et al. Stimulation of N-methyl-D-aspartate receptor-mediated calcium entry into dissociated neurons by reduced and oxidized glutathione. Mol Pharmacol 1992;41:308-314.

92. Banday AA, Lokhandwala MF. Oxidative stress reduces renal dopamine D1 receptor-Gq/11alpha $\mathrm{G}$ protein-phospholipase $\mathrm{C}$ signaling involving G protein-coupled receptor kinase 2. Am J Physiol Renal Physiol 2007;293:F306-F315.

93. Steullet P, Neijt HC, Cuenod M, Do KQ. Synaptic plasticity impairment and hypofunction of NMDA receptors induced by glutathione deficit: relevance to schizophrenia. Neuroscience 2006;137:807-819.

94. Gawryluk JW, Wang JF, Andreazza AC, Shao L, Young LT. Decreased levels of glutathione, the major brain antioxidant, in post-mortem prefrontal cortex from patients with psychiatric disorders. Int J Neuropsychopharmacol 2011;14:123-130.

95. Gysin R, Kraftsik R, Sandell J, Bovet P, Chappuis C, Conus P, et al. Impaired glutathione synthesis in schizophrenia: convergent genetic and functional evidence. Proc Natl Acad Sci U S A 2007;104:16621-16626.

96. Rabinovic AD, Hastings TG. Role of endogenous glutathione in the oxidation of dopamine. J Neurochem 1998;71:2071-2078.

97. Tosic M, Ott J, Barral S, Bovet P, Deppen P, Gheorghita F, et al. Schizophrenia and oxidative stress: glutamate cysteine ligase modifier as a susceptibility gene. Am J Hum Genet 2006;79:586-592.

98. Do KQ, Trabesinger AH, Kirsten-Kruger M, Lauer CJ, Dydak U, Hell $D$, et al. Schizophrenia: glutathione deficit in cerebrospinal fluid and prefrontal cortex in vivo. Eur J Neurosci 2000;12:3721-3728.

99. Yao JK, Reddy RD, van Kammen DP. Oxidative damage and schizophrenia: an overview of the evidence and its therapeutic implications. CNS Drugs 2001;15:287-310.

100. Yao JK, Leonard S, Reddy R. Altered glutathione redox state in schizo- phrenia. Dis Markers 2006;22:83-93.

101. Matsuzawa D, Obata T, Shirayama Y, Nonaka H, Kanazawa Y, Yoshitome E, et al. Negative correlation between brain glutathione level and negative symptoms in schizophrenia: a $3 \mathrm{~T}$ 1H-MRS study. PLoS One 2008;3:e1944.

102. Dean OM, van den Buuse M, Bush AI, Copolov DL, Ng F, Dodd S, et al. A role for glutathione in the pathophysiology of bipolar disorder and schizophrenia? Animal models and relevance to clinical practice. Curr Med Chem 2009;16:2965-2976.

103. Cataldo AM, McPhie DL, Lange NT, Punzell S, Elmiligy S, Ye NZ, et al. Abnormalities in mitochondrial structure in cells from patients with bipolar disorder. Am J Pathol 2010;177:575-585.

104. Fattal O, Budur K, Vaughan AJ, Franco K. Review of the literature on major mental disorders in adult patients with mitochondrial diseases. Psychosomatics 2006;47:1-7.

105. Sproule DM, Kaufmann P. Mitochondrial encephalopathy, lactic acidosis, and strokelike episodes: basic concepts, clinical phenotype, and therapeutic management of MELAS syndrome. Ann N Y Acad Sci 2008;1142:133-158.

106. Hruszkewycz AM. Lipid peroxidation and mtDNA degeneration. A hypothesis. Mutat Res 1992;275:243-248.

107. Kowaltowski AJ, Vercesi AE. Mitochondrial damage induced by conditions of oxidative stress. Free Radic Biol Med 1999;26:463-471.

108. Chen JJ, Yu BP. Alterations in mitochondrial membrane fluidity by lipid peroxidation products. Free Radic Biol Med 1994;17:411-418.

109. Keller JN, Mark RJ, Bruce AJ, Blanc E, Rothstein JD, Uchida K, et al. 4-Hydroxynonenal, an aldehydic product of membrane lipid peroxidation, impairs glutamate transport and mitochondrial function in synaptosomes. Neuroscience 1997;80:685-696.

110. Hazlett EA, Buchsbaum MS, Kemether E, Bloom R, Platholi J, Brickman AM, et al. Abnormal glucose metabolism in the mediodorsal nucleus of the thalamus in schizophrenia. Am J Psychiatry 2004;161:305314.

111. Martins-de-Souza D, Harris LW, Guest PC, Bahn S. The role of energy metabolism dysfunction and oxidative stress in schizophrenia revealed by proteomics. Antioxid Redox Signal 2011;15:2067-2079.

112. Keating DJ. Mitochondrial dysfunction, oxidative stress, regulation of exocytosis and their relevance to neurodegenerative diseases. J Neurochem 2008;104:298-305.

113. Muller N, Krause D, Dehning S, Musil R, Schennach-Wolff R, Obermeier $\mathrm{M}$, et al. Celecoxib treatment in an early stage of schizophrenia: results of a randomized, double-blind, placebo-controlled trial of celecoxib augmentation of amisulpride treatment. Schizophr Res 2010;121: 118-124.

114. Akhondzadeh S, Tabatabaee M, Amini H, Ahmadi Abhari SA, Abbasi $\mathrm{SH}$, Behnam B. Celecoxib as adjunctive therapy in schizophrenia: a double-blind, randomized and placebo-controlled trial. Schizophr Res 2007;90:179-185.

115. Laan W, Grobbee DE, Selten JP, Heijnen CJ, Kahn RS, Burger H. Adjuvant aspirin therapy reduces symptoms of schizophrenia spectrum disorders: results from a randomized, double-blind, placebo-controlled trial. J Clin Psychiatry 2010;71:520-527.

116. Rapaport MH, Delrahim KK, Bresee CJ, Maddux RE, Ahmadpour O, Dolnak D. Celecoxib augmentation of continuously ill patients with schizophrenia. Biol Psychiatry 2005;57:1594-1596.

117. Sommer IE, de Witte L, Begemann M, Kahn RS. Nonsteroidal antiinflammatory drugs in schizophrenia: ready for practice or a good start? A meta-analysis. J Clin Psychiatry 2012;73:414-419.

118. Berk M, Copolov D, Dean O, Lu K, Jeavons S, Schapkaitz I, et al. Nacetyl cysteine as a glutathione precursor for schizophrenia--a doubleblind, randomized, placebo-controlled trial. Biol Psychiatry 2008;64: 361-368.

119. Lavoie S, Murray MM, Deppen P, Knyazeva MG, Berk M, Boulat O, et al. Glutathione precursor, $\mathrm{N}$-acetyl-cysteine, improves mismatch negativity in schizophrenia patients. Neuropsychopharmacology 2008; 
33:2187-2199.

120. Zhang XY, Zhou DF, Zhang PY, Wu GY, Su JM, Cao LY. A doubleblind, placebo-controlled trial of extract of Ginkgo biloba added to haloperidol in treatment-resistant patients with schizophrenia. J Clin Psychiatry 2001;62:878-883.

121. Zhang XY, Zhou DF, Su JM, Zhang PY. The effect of extract of ginkgo biloba added to haloperidol on superoxide dismutase in inpatients with chronic schizophrenia. J Clin Psychopharmacol 2001;21:85-88.

122. Zhou D, Zhang X, Su J, Nan Z, Cui Y, Liu J, et al. The effects of classic antipsychotic haloperidol plus the extract of ginkgo biloba on superoxide dismutase in patients with chronic refractory schizophrenia. Chin Med J (Engl) 1999;112:1093-1096.

123. Singh V, Singh SP, Chan K. Review and meta-analysis of usage of ginkgo as an adjunct therapy in chronic schizophrenia. Int J Neuropsychopharmacol 2010;13:257-271.

124. Sandyk R, Kanofsky JD. Vitamin C in the treatment of schizophrenia. Int J Neurosci 1993;68:67-71.

125. Suboticanec K, Folnegovic-Smalc V, Korbar M, Mestrovic B, Buzina R. Vitamin C status in chronic schizophrenia. Biol Psychiatry 1990;28: 959-966.

126. Pitt B. Letter: Vitamin C and schizophrenia. Lancet 1974;2:1153-1154.

127. Dakhale GN, Khanzode SD, Khanzode SS, Saoji A. Supplementation of vitamin $\mathrm{C}$ with atypical antipsychotics reduces oxidative stress and improves the outcome of schizophrenia. Psychopharmacology (Berl) 2005;182:494-498.

128. Miller BJ, Buckley P, Seabolt W, Mellor A, Kirkpatrick B. Meta-analysis of cytokine alterations in schizophrenia: clinical status and antipsychotic effects. Biol Psychiatry 2011;70:663-671.

129. Kato T, Mizoguchi Y, Monji A, Horikawa H, Suzuki SO, Seki Y, et al. Inhibitory effects of aripiprazole on interferon-gamma-induced microglial activation via intracellular $\mathrm{Ca} 2+$ regulation in vitro. J Neurochem 2008;106:815-825.

130. Kato T, Monji A, Hashioka S, Kanba S. Risperidone significantly inhibits interferon-gamma-induced microglial activation in vitro. Schizophr Res 2007;92:108-115.

131. Hou Y, Wu CF, Yang JY, He X, Bi XL, Yu L, et al. Effects of clozapine, olanzapine and haloperidol on nitric oxide production by lipopoly- saccharide-activated N9 cells. Prog Neuropsychopharmacol Biol Psychiatry 2006;30:1523-1528.

132. Kowalski J, Labuzek K, Herman ZS. Flupentixol and trifluperidol reduce secretion of tumor necrosis factor-alpha and nitric oxide by rat microglial cells. Neurochem Int 2003;43:173-178.

133. Labuzek K, Kowalski J, Gabryel B, Herman ZS. Chlorpromazine and loxapine reduce interleukin-1beta and interleukin-2 release by rat mixed glial and microglial cell cultures. Eur Neuropsychopharmacol 2005; 15:23-30.

134. Halim ND, Weickert CS, McClintock BW, Weinberger DR, Lipska BK. Effects of chronic haloperidol and clozapine treatment on neurogenesis in the adult rat hippocampus. Neuropsychopharmacology 2004; 29:1063-1069.

135. Padurariu M, Ciobica A, Dobrin I, Stefanescu C. Evaluation of antioxidant enzymes activities and lipid peroxidation in schizophrenic patients treated with typical and atypical antipsychotics. Neurosci Lett 2010;479:317-320.

136. Park SW, Lee CH, Lee JG, Kim LW, Shin BS, Lee BJ, et al. Protective effects of atypical antipsychotic drugs against MPP(+)-induced oxidative stress in PC12 cells. Neurosci Res 2011;69:283-290.

137. Wang H, Xu H, Dyck LE, Li XM. Olanzapine and quetiapine protect PC12 cells from beta-amyloid peptide(25-35)-induced oxidative stress and the ensuing apoptosis. J Neurosci Res 2005;81:572-580.

138. Dakhale G, Khanzode S, Saoji A, Khobragade L, Turankar A. Oxidative damage and schizophrenia: the potential benefit by atypical antipsychotics. Neuropsychobiology 2004;49:205-209.

139. Zhang XY, Zhou DF, Shen YC, Zhang PY, Zhang WF, Liang J, et al. Effects of risperidone and haloperidol on superoxide dismutase and nitric oxide in schizophrenia. Neuropharmacology 2012;62:1928-1934.

140. Zhang XY, Zhou DF, Cao LY, Zhang PY, Wu GY, Shen YC. The effect of risperidone treatment on superoxide dismutase in schizophrenia. J Clin Psychopharmacol 2003;23:128-131.

141. Zhang XY, Tan YL, Cao LY, Wu GY, Xu Q, Shen Y, et al. Antioxidant enzymes and lipid peroxidation in different forms of schizophrenia treated with typical and atypical antipsychotics. Schizophr Res 2006; 81:291-300. 